\title{
Neuropatia paraneoplásica associada ao mastocitoma canino
}

\author{
Paraneoplastic neuropathy associated with canine mast cell tumor
}

\author{
Sabrina Marin Rodigheri ${ }^{{ }^{*}}$ Carlos Roberto Daleck $^{\mathrm{II}}$ Sabryna Gouveia Calazans ${ }^{\mathrm{I}}$ \\ Simone Crestoni Fernandes ${ }^{\mathrm{I}}$ Andrigo Barboza De Nardi' ${ }^{\mathrm{III}}$ Jane Regina França Cesar ${ }^{\mathrm{I}}$ \\ João Humberto Teotônio de Castro ${ }^{I}$
}

\begin{abstract}
As síndromes paraneoplásicas compreendem um grupo diverso de alterações clínicas associadas a neoplasias e ocorrem em sítios distantes do tumor primário ou de suas metástases. As neuropatias paraneoplásicas são distúrbios raros em cães, mas representam morbidade significativa e servem como importantes indicadores diagnósticos e prognósticos. $O$ presente trabalho relata a ocorrência de dois casos de neuropatia paraneoplásica em cães com mastocitoma, considerando a apresentação clínica, o diagnóstico e as formas de tratamento utilizadas.
\end{abstract}

Palavras-chave: oncologia, síndromes paraneoplásicas, sistema nervoso, cão.

\section{ABSTRACT}

Paraneoplastic syndromes comprise a diverse group of clinical anomalies associated with neoplasias and occur in a location distant from the primary tumor or of your metastasis. Paraneoplastic neuropathy are rare disturbs in dogs, but represent significant morbidity and are useful as diagnostic and prognostic indicators. This work report the occurrence of two cases of paraneoplastic neuropathy in dogs with mast cell tumor, considering the clinical signs, diagnosis and treatment used.

Key words: oncology, paraneoplastic syndromes, nervous, system, dog.
O mastocitoma é um neoplasma comum em cães, representando de 7 a 21\% dos tumores cutâneos da espécie. Acomete animais adultos e idosos, com idades médias de 9 anos, principalmente das raças Boxer, Beagle, Basset hound, Buldogue, Boston terrier, Labrador e Schnauzer (FOX, 2002; THAMM \& VAIL, 2007).

As síndromes paraneoplásicas representam um grupo heterogêneo de alterações clínicas associadas ao câncer, que decorrem de ações não-invasivas do neoplasma (MORRISON, 2002; CULLEN et al., 2002; BERGMAN, 2007). A incidência dessas alterações ainda é desconhecida na Medicina Veterinária, mas aproximadamente $75 \%$ dos pacientes humanos com câncer apresentam algum distúrbio paraneoplásico durante a evolução da doença (MORRISON, 2002).

Sabe-se que as neoplasias podem induzir o desenvolvimento de lesões no sistema nervoso mediante efeitos indiretos ou paraneoplásicos, ou seja, na ausência de compressão tecidual, infiltração local primária ou metastática. Nessas condições, não são detectadas células tumorais nas diferentes estruturas neuronais, incluindo cérebro, medula espinhal, nervos cranianos, nervos periféricos ou junções neuromusculares (BRAUND, 1990). Essas complicações neurológicas podem acompanhar o desenvolvimento

\footnotetext{
'Programa de Pós-graduação em Cirurgia Veterinária, Departamento de Clínica e Cirurgia Veterinária, Faculdade de Ciências Agrárias e Veterinárias (FCAV), Universidade Estadual Paulista (UNESP), Campus de Jaboticabal. Via de acesso Prof. Paulo Donatto Castelane, s/n, 14884-900, Jaboticabal, SP, Brasil. E-mail: smrodigheri@yahoo.com.br. *Autor para correspondência. "Departamento de Clínica e Cirurgia Veterinária, FCAV, UNESP, Jaboticabal, SP, Brasil.

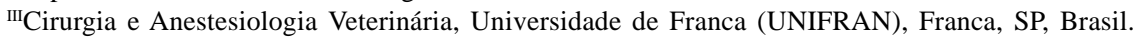


tumoral ou anteceder a detecção clínica do neoplasma (KRARUP \& CRONE, 2002).

Objetiva-se com este trabalho relatar dois casos de neuropatia paraneoplásica (NP) associada ao mastocitoma canino, considerando a apresentação clínica, o diagnóstico e as formas de tratamento utilizadas.

Dois cães foram encaminhados ao Serviço de Oncologia de um Hospital Veterinário manifestando sinais neurológicos concomitantes ao desenvolvimento de nódulos cutâneos. O primeiro paciente, um macho, da raça Doberman Pinscher, com nove anos de idade, apresentava histórico de tetraparesia não relacionada a trauma, com evolução de 24 horas. O proprietário referiu que há duas semanas o animal demonstrara fraqueza em membros pélvicos, a qual evoluíra gradualmente a tetraparesia. Além disso, foi relatada a presença de um nódulo cutâneo localizado na região inguinal, com crescimento acelerado e evolução de oito dias. Ao exame físico, foi constatado que o tumor apresentava $7 \mathrm{~cm}$ de diâmetro, consistência firme, abrangência dermosubcutânea e intenso edema peritumoral. Ao exame neurológico, observaram-se nocicepção profunda preservada, hiporreflexia e hipotonia muscular em membros torácicos e pélvicos. Não foram detectadas alterações em nervos cranianos.

O segundo paciente, uma fêmea, sem raça definida, com 12 anos de idade, apresentava histórico de apatia, hiporexia, incoordenação e inclinação da cabeça, com evolução de 24 horas. O proprietário referiu a presença de um nódulo cutâneo localizado na região lateral do tórax com dois meses de evolução, porém com crescimento acelerado nos últimos cinco dias. Ao exame físico, foi constatado que o tumor apresentava $8 \mathrm{~cm}$ de diâmetro, abrangência dermosubcutânea, consistência firme e intenso edema peritumoral. Ao exame neurológico, constataram-se síndrome vestibular caracterizada por head tilt e nistagmo horizontal com fase rápida para a esquerda. Não foram detectadas alterações em nervos cranianos e reflexos espinhais. À avaliação clínica dos condutos auditivos, não foram detectadas alterações.

Objetivando a avaliação clínica completa dos pacientes e a exclusão das principais causas de neuropatia em cães, procedeu-se à realização de alguns exames laboratoriais, incluindo hemograma, urinálise, glicemia, alanino aminotransferase, creatinina e cálcio ionizado. Foram detectadas alterações apenas no eritrograma do segundo paciente, o qual apresentou anemia normocítica normocrômica regenerativa $(\mathrm{Ht}=12 \%)$. O exame citológico do tumor conferiu o diagnóstico de mastocitoma em ambos os cães. À avaliação radiográfica do tórax, não foram evidenciadas alterações compatíveis com metástase pulmonar.

O primeiro paciente foi submetido à avaliação radiográfica da coluna tóraco-lombar em incidências látero-lateral e ventro-dorsal, porém não foram visualizadas alterações. O segundo paciente foi submetido a transfusão sangüínea e administração de ranitidina (2mg kg-1, via subcutânea) e difenidramina (1 $\mathrm{mg} \mathrm{kg}^{-1}$, via intra-muscular). À análise do líquor de ambos pacientes, não se constataram alterações.

Devido a suspeita de NP e à impossibilidade de ressecção cirúrgica imediata de ambos os neoplasmas, foi instituída quimioterapia antineoplásica pré-operatória. O protocolo quimioterápico incluiu a administração de prednisona (1 $\mathrm{mg} \mathrm{kg}^{-1}$, a cada 24 horas, via oral, durante 15 dias, seguido de $0,5 \mathrm{mg} \mathrm{kg}^{-1}$, a cada 24 horas, via oral, durante 7 dias) e sulfato de vimblastina ( $2 \mathrm{mg} \mathrm{m}^{-2}$, a cada 7 dias, via intravenosa, durante três sessões). Este protocolo foi associado à terapia anti-histamínica com ranitidina ( $2 \mathrm{mg} \mathrm{kg}^{-1}$, a cada 12 horas, via oral, durante 30 dias) e difenidramina (4mg $\mathrm{kg}^{-1}$, a cada 24 horas, via oral, durante 30 dias). A resposta terapêutica foi semelhante nos dois pacientes, ocorrendo resolução completa do quadro neurológico poucos dias após o início da quimioterapia. No sétimo dia de tratamento, ambos os proprietários referiram ausência de alterações sistêmicas e redução significativa do diâmetro tumoral. Após a terceira sessão de quimioterapia (21 dias), foi realizada a exérese cirúrgica dos tumores. No pós-operatório, não foi instituído protocolo quimioterápico adjuvante. À avaliação histopatológica, confirmou-se o diagnóstico de mastocitoma grau II em ambos os pacientes. O primeiro paciente encontrava-se em boas condições clínicas 60 dias após a cirurgia, isento de alterações neurológicas. O segundo paciente apresentou recidiva neoplásica irresponsiva à quimioterapia 90 dias após a cirurgia, evoluindo a óbito. Contudo, durante o período de sobrevida, não apresentou sinais de comprometimento neurológico.

Os distúrbios paraneoplásicos do sistema nervoso têm se tornado freqüentes em seres humanos, porém, em animais, a incidência dessas alterações ainda é desconhecida (MORRISON, 2002; VINCENT, 2005). MEUTEN (2002) citou a ocorrência de neuropatia paraneoplásica em apenas dois animais da espécie canina. As NPs podem ser classificadas como centrais ou periféricas e clínicas ou subclínicas. As centrais são denominadas encefalite límbica, degeneração cerebelar, mielinólise pontinocentral e mielopatia necrotizante subaguda; e as periféricas, neuropatia sensorimotora, neuronopatia sensorial subaguda e Miastenia gravis. Estudos demonstram que as 
neuropatias periféricas subclínicas acometem de 17 a 50\% dos pacientes humanos com câncer, mas apenas 2 a 5\% manifestam a doença clinicamente (BRAUND, 1990). Os principais neoplasmas associados a neuropatias em seres humanos são carcinoma broncogênico, carcinoma mamário e linfoma (ALTAHA, 2003; WADA, 2003). BRAUND et al. (1987) demonstraram a presença de lesões degenerativas em nervos periféricos de 59\% dos cães com carcinoma broncogênico, 59\% com adenocarcinoma mamário, 48\% com melanoma, $47 \%$ com insulinoma, $39 \%$ com osteossarcoma e $32 \%$ com mastocitoma. As principais alterações observadas nas fibras neuronais são desmielinização, vasculite e degeneração axonal (KUNTZER et al., 2004; BERGMAN, 2007).

Conforme observado nos referidos casos, as NPs podem manifestar-se como lesões focais ou difusas. Os principais sinais clínicos das NPs são fraqueza, intolerância a exercícios, hipotonia muscular, paresia ou paralisia de membros torácicos e/ou pélvicos, atrofia muscular neurogênica e reflexos espinhais reduzidos ou ausentes (BRAUND et al., 1987), conforme observado no primeiro paciente. Lesões focais semelhantes às observadas no segundo paciente são pouco relatadas em seres humanos e não foram descritas em animais (ALTAHA, 2003).

Embora a patogênese das NPs não tenha sido elucidada, acredita-se que a origem das lesões neurológicas seja auto-imune, não havendo relação com distúrbios metabólicos, nutricionais, traumáticos, infecciosos ou tóxicos (BRAUND, 1990; VINCENT, 2005). Estudos sorológicos em seres humanos demonstraram a existência de anticorpos antineurais em pacientes com NP. Pesquisas recentes revelam que alguns anticorpos podem servir como marcadores para NPs específicas, bem como para determinados tipos tumorais (VINCENT, 2005). Em animais, ainda não existem estudos relacionados à pesquisa destes anticorpos; desta forma, não foi realizada a mensuração dos anticorpos antineurais nos referidos pacientes.

Além da natureza auto-imune, acredita-se na participação de citocinas pró-inflamatórias e na influência das vasculopatias na patogênese das NPs (MORRISON, 2002; WADA, 2003; KUNTZER et al., 2004). Sabe-se que os grânulos dos mastócitos contêm uma série de compostos biologicamente ativos, incluindo histamina, heparina, fator ativador de plaquetas, fator de necrose tumoral, prostaglandinas, leucotrienos, hidrolases ácidas, catepsinas e carboxipeptidades. Dessa forma, a degranulação dos mastócitos neoplásicos induz uma série de manifestações sistêmicas, incluindo ulceração gástrica, inflamação peritumoral, alterações cardiopulmonares, tempo de sangramento prolongado e atraso na cicatrização (FOX, 2002). A ocorrência destes dois casos de NP em cães com mastocitoma alerta para a necessidade de pesquisas relacionando a degranulação mastocitária com distúrbios neurológicos paraneoplásicos.

O diagnóstico definitivo das NPs é extremamente difícil, constituindo-se do histórico do paciente, de exame físico e neurológico e da exclusão de outras enfermidades que possam ocasionar neuropatias e eletroneuromiografia (MARIANI et al., 1999). Inúmeras etiologias podem ser atribuídas às diferentes neuropatias em cães, incluindo distúrbios metabólicos, nutricionais, infecciosos, tóxicos, traumáticos, degenerativos e idiopáticos (MARIANI et al., 1999). Em ambos os pacientes descritos, não foram detectadas alterações clínicas e laboratoriais compatíveis com doença sistêmica concomitante à neoplasia. Além disso, a excelente recuperação dos cães após a instituição da quimioterapia antineoplásica, com ausência de recidiva dos sinais neurológicos após a exérese tumoral, sugerem a ocorrência de NP.

Em seres humanos, o tratamento das NPs é fundamentado no tratamento da neoplasia primária ou mestastática, na imunossupressão e/ou na administração de glicocorticóides, porém, resultados satisfatórios são observados apenas na ausência de desmielinização ou degeneração axonal severas (MARIANI et al., 1999).

As neoplasias malignas podem induzir síndromes neurológicas paraneoplásicas clínicas ou subclínicas. Dessa forma, é importante incluir as NPs no diagnóstico diferencial de cães idosos com distúrbios neurológicos, bem como incentivar pesquisas relacionadas a patogenia, métodos de diagnóstico e tratamento de tais alterações em animais.

\section{REFERÊNCIAS}

ALTAHA, R.; ABRAHAM, J. Paraneoplastic neurologic syndrome associated with occult breast cancer: a case report and review of literature. Breast Journal, v.9, n.5, p.417419, 2003

BERGMAN, P.J. Paraneoplastic syndromes. In: WITHROW, S.J.; VAIL, D.M. Small animal clinical oncology. 4.ed. St. Louis: Saunders Elsevier, 2007. Cap.5. p.77-94.

BRAUND, K.G. et al. Peripheral neuropathy associated with malignant neoplasms in dogs. Veterinary Pathology, v.24, p.16-21, 1987.

BRAUND, K.G. Remote effects of cancer on the nervous system. Seminars in Veterinary Medicine and Surgery (Small Animal), v.5, n.4, p.262-270, 1990. 
CULLEN, J.M. et al. An overview of cancer patogenesis, diagnosis and management. In: MEUTEN, D.J. Tumors in domestic animals. 4.ed. Iowa: Iowa Estate, 2002. Cap.1, p.22-24.

FOX, L.E. Mast cell tumors. In: MORRISON, W.B. Cancer in dogs and cats. 2.ed. Baltimore: Williams \& Wilkins, 2002. Cap.30, p.451-458.

KRARUP, C.; CRONE, C. Neurophysiological studies in malignant disease with particular reference to involvement of peripheral nerves. Journal of Neurololy, v.249, p.651-661, 2002.

KUNTZER, T. et al. Clinical features and pathophysiological basis of sensory neuronopathies. Muscle \& Nerve, v.30, p.255268, 2004.

MARIANI, C.L. et al. Paraneoplastic poyneuropathy and subsequent recovery following tumor removal in a dog. Journal of the American Animal Hospital Association, v.35, p.302305, 1999.

MORRISON, W.B. Paraneoplastic syndromes and the tumors that cause them. In: MORRISON, W.B. Cancer in dogs and cats. 2.ed. Baltimore: Williams \& Wilkins, 2002. Cap.52, p. 731-743.

THAMM, D.H.; VAIL, D.M. Mast cell tumors. In: WITHROW, S.J.; VAIL, D.M. Small animal clinical oncology. 4.ed. St. Louis: Saunders Elsevier, 2007. Cap.19, p. $402-424$.

VINCENT, A. Antibodies associated with paraneoplastic neurological disorders. Neurological Science, v.26, p.S3-S4, 2005.

WADA, M. et al. A case of inflammatory demyelinating polyradiculoneuropathy associated with T-cell lymphoma. Acta Neurologica Scandinavica, v.107, p.62-66, 2003. 